\title{
Low levels of chemical anthropogenic pollution may threaten amphibians by impairing predator recognition
}

Nuria Polo-Cavia ${ }^{\mathrm{a},{ }^{*}} \cdot$ Pablo Burraco ${ }^{\mathrm{b}} \cdot$ Ivan Gomez-Mestre ${ }^{\mathrm{b},{ }^{*}}$

a Department of Biology, Universidad Autónoma de Madrid, 28049 Madrid, Spain

${ }^{\mathrm{b}}$ Ecology, Evolution, and Development Group, Department of Wetland Ecology,

Doñana Biological Station, CSIC, E-41092 Seville, Spain

*Corresponding authors. E-mail address: nuria.polo@uam.es (N. Polo-Cavia) and igmestre@ebd.csic.es (I. Gomez-Mestre). 


\section{ABSTRACT}

Recent studies suggest that direct mortality and physiological effects caused by pollutants are major contributing factors to global amphibian decline. However, even sublethal concentrations of pollutants could be harmful if they combined with other factors to cause high mortality in amphibians. Here we show that sublethal concentrations of pollutants can disrupt the ability of amphibian larvae for predator recognition, hence increasing their risk of predation. This effect is indeed much more important since very low amounts of pollutants are ubiquitous, and environmental efforts are mostly directed towards preventing lethal spills. We analyzed the effects of two common contaminants (humic acid and ammonium nitrate) on the ability of tadpoles of the western spadefoot toad (Pelobates cultripes) to recognize chemical cues from a common predator, nymphs of the dragonfly Anax imperator. We compared tadpoles' swimming activity in the presence and absence of water-borne chemical cues from dragonflies, at different concentrations of humic acid and ammonium nitrate. Tadpoles reduced swimming activity in response to predator cues in the absence of pollutants, whereas they remained unresponsive to these cues when either humic acid or ammonium nitrate were added to the water, even at low concentrations. Moreover, changes in tadpole activity associated with the pollutants themselves were nonsignificant, indicating no clear toxic effect. Alteration of the natural chemical environment of aquatic systems by pollutants may be an important contributing cause for declines in amphibian populations, even at sublethal concentration.

Keywords: amphibians; ammonium nitrate; chemical cues; humic acid; predator recognition; water pollutants 


\section{Introduction}

Chemical pollutants have been pointed out as one of the major drivers of humaninduced environmental change (Millennium Ecosystem Assessment, 2005; Sih et al., 2011; Diamond, 2015). Pollutants are indeed considered among the five ultimate factors causing global decline of amphibians, the most vulnerable group of vertebrates (approximately $41 \%$ of the species endangered; Hoffmann et al., 2010). Most studies to date describe wastewater contaminants as a major threat to amphibian species, based on their lethal physiological and toxicological effects (see Egea-Serrano et al., 2012). However, sublethal levels of pollution can act indirectly causing physiological stress, reduced growth rates, or developmental and reproductive failures in amphibian populations (Boone and Bridges, 2006; Hayes et al., 2010; Baker et al., 2013). Pollution may also critically affect amphibians by disrupting chemoreception and altering individual behavior (Lürling and Scheffer, 2007; Lürling, 2012).

Chemical communication is of primary importance, particularly in aquatic systems that have poor lighting conditions, which reduce the effectiveness of visual signals, and where many organisms rely primarily on semiochemicals for mate recognition and predator detection (Brönmark and Hansson, 2000; Johansson and Jones, 2007). Accurate detection and recognition of chemical information released by predators, or by prey under attack, allow aquatic prey to respond plastically through inducible defenses (Chivers and Smith, 1998; Kats and Dill, 1998). Prey can often alter their morphology, life history, and/or behavior upon detection of predator kairomones, i.e., a predator's signature odor (Sih and Moore, 1993; Tollrian and Harvell, 1999; Lass et al., 2005; Chivers et al., 2008; see Ferrari et al., 2010 for an extensive review). Such plastic antipredator responses are generally fine-tuned to the level of risk experienced 
(Van Buskirk and Arioli, 2002; McCoy et al., 2012) and are the result of joint evolutionary history between predator and prey (Ferrari et al., 2010).

However, various anthropogenic activities have resulted in the contamination of freshwater ecosystems with a wide array of harmful contaminants (i.e., pesticides, herbicides, fertilizers, or heavy metals) (Kolpin et al., 2002; Carpenter et al., 2011; Lürling, 2012; Rasmussen et al., 2015). In addition to their direct toxic effects, chemical pollutants released in freshwater habitats alter the chemical environment, causing interferences in the cue recognition systems of aquatic organisms and impairing chemoreception (Seehausen et al., 1997; Wolf and Moore, 2002; Fabian et al., 2007). Disruption of chemical communication may have drastic ecological and evolutionary consequences, affecting foraging, navigation, mate choice, species recognition, and possibly predator detection or evasion (Brönmark and Hansson, 2000; Wolf and Moore, 2002; Wyatt, 2003; Fisher et al., 2006; Ward et al., 2008; Gill and Raine, 2014).

In water, some contaminants may bind to pheromones and block or damage chemoreceptors (Hubbard et al., 2002; Yang et al., 2002; Mesquita et al., 2003). For instance, elevated levels of humic acid are known to reduce the olfactory response of goldfish (Carassius auratus) and other teleosts to sexual pheromones (Hubbard et al., 2002). Humic acid also promotes hybridization of poeciliid fish (Xiphophorus sp.) due to female loss of their mating preferences for conspecific males (Fisher et al., 2006), and has been demonstrated to interfere with species recognition in zebrafish (Danio rerio, Fabian et al., 2007). Likewise, chemical pollutants could affect predator-prey recognition in aquatic organisms by impairing chemical detection of predators (Dodson et al., 1995; Preston et al., 1999a,b; Schulz and Dabrowski, 2001).

Chemical pollution can affect many aquatic animals, but impacts on amphibian species are of special concern due to global declines of amphibian populations in the 
last decades (Hoffmann et al., 2010). Amphibian declines are correlated with proximity to agricultural lands (Bishop et al., 1999; Joly et al., 2001; Davidson, 2004), likely as a result of runoff of pesticides and fertilizers (Relyea et al., 2005; Relyea and Hoverman, 2006; Miaud et al., 2011). Ecologists have made a great effort to understand direct toxicological impacts of pesticides on larval amphibians (Diana et al., 2000; Boone and Semlitsch, 2001, 2002; Boone et al., 2001; Boone and Bridges, 2003; Boone and James, 2003; Sparling et al., 2010; Egea-Serrano et al., 2012), and studies have also addressed the synergistic effects of pesticides and predator cues on tadpole activity (Bridges, 1999; Rohr and Crumrine, 2005; Relyea and Edwards, 2010), growth (Kerby et al., 2011) and survival rates (Relyea and Mills, 2001; Relyea, 2003a, 2005). Nevertheless, the complex indirect effects of chemical pollutants that arise from disrupted sensory systems of tadpoles remain unclear (but see Mandrillon and Saglio, 2007). Many amphibian larvae respond to water-borne predator cues by strongly reducing their activity levels, thus avoiding detection in predator encounters (Stauffer and Semlitsch, 1993; Wilson and Lefcort, 1993; Holomutzki, 1995; Kiesecker et al., 1996; reviewed in Kats and Dill, 1998; Chivers and Smith, 1998). However, anthropogenic chemicals directly or indirectly spilled on freshwater ecosystems might interfere with tadpoles' ability to recognize predator cues, hence seriously compromising their odds of survival.

Here we examine the effects of anthropogenic alteration of the chemical environment on the ability of tadpoles of the western spadefoot toad (Pelobates cultripes) to accurately respond to chemical cues from a common predator, nymphs of the dragonfly Anax imperator. We compared swimming activity of tadpoles in the presence and absence of water-borne chemical cues from dragonflies, at different concentrations of two contaminants that are commonly present in freshwater habitats as a consequence of human activities: humic acid (HA) and ammonium nitrate (AN). HA 
is a naturally occurring substance in aquatic environments resulting from biodegradation of dead organic matter, but, associated to agricultural manure, it may highly increase due to eutrophication (Thomas, 1997; Atiyeh et al., 2002; Kappler and Haderlein, 2003). HA is known to alter natural behaviors of aquatic species by disturbing their sensory environment (Hubbard et al., 2002; Fisher et al., 2006; Fabian et al., 2007). On the other hand, nitrogen pollution resulting from agricultural runoff, including AN, negatively affects growth and development of embryos, and reduces larval survival in several amphibian species (Marco et al., 1999; Jofre and Karasov, 1999; Laposata and Dunson, 2000; De Solla et al., 2002; Ortiz et al., 2004; Griffis-Kyle, 2005; Ortiz-Santaliestra et al., 2007). In addition, nitrates may influence tadpole behavior and affect the outcome of competition and predation in the amphibian larval guild (Smith et al., 2006). We hypothesize that the presence of either HA or AN in water could interfere the ability of tadpoles to discriminate and adaptively respond to chemical cues from their natural predators, disrupting their behavioral defenses (i.e., reduced activity in the presence of predators) and increasing prey detectability.

\section{Materials and methods}

\subsection{Animal care and housing}

We collected 50 eggs (Gosner stages 10-12, Gosner 1960) from each of three clutches of western spadefoot toad ( $P$. cultripes) at a temporary peridune pond $\left(36^{\circ} 59^{\prime} \mathrm{N},-6^{\circ} 30^{\prime} \mathrm{W}\right)$ within the Biological Reserve of Doñana (southwest Spain) and transported them to walk-in climatic chambers $\left(16^{\circ} \mathrm{C}, 12: 12 \mathrm{~L}: \mathrm{D}\right)$ at the Doñana Biological Station in Seville. In the laboratory, eggs from the three clutches were pooled 
together and placed on two 5 L plastic trays with carbon-filtered dechlorinated water and aerators until hatching. Experimental tadpoles were, hence, not in contact with predator cues prior to the experiments. When tadpoles reached the free-feeding stage (Gosner stage 25), tadpoles were haphazardly allocated to $3 \mathrm{~L}$ plastic buckets filled with carbon-filtered dechlorinated tap water, where they were raised individually at $20{ }^{\circ} \mathrm{C}$ and under a natural photoperiod (12:12 L:D). We renewed water twice weekly and tadpoles were fed with ground rabbit chow ad libitum.

We also captured dragonfly nymphs (A. imperator) at several ponds within the park, to be used as predator cue donors. Dragonflies (3-5 $\mathrm{cm}$ length) were also housed individually in $1 \mathrm{~L}$ plastic buckets in a climatic chamber $\left(20^{\circ} \mathrm{C}, 12: 12 \mathrm{~L}: \mathrm{D}\right)$ separated from that of tadpoles, to avoid chemical or visual contact with the predators prior to the experiments. To provide necessary perches to the nymphs, we placed plastic plants in all aquaria, thoroughly rinsed to eliminate any artificial cues.

\subsection{Predator cue preparation}

To prepare predator chemical cues, we filled each donor dragonfly container with 0.5 L of dechlorinated tap water, to be pervaded with predator cues. Dragonflies were fed $P$. cultripes tadpoles, once per day. This way, predator cues contained dragonfly kairomones, but also alarm cues and post-digestion cues from conspecific tadpoles, better reflecting natural conditions. Since predator cues last approximately $2-4$ days in water (Peacor, 2006), we extracted and mixed the water from three dragonfly aquaria every two days, and froze it in $10 \mathrm{ml}$ aliquots at $-20^{\circ} \mathrm{C}$ until use (Woody and Mathis, 1998; Gonzalo et al., 2007; Polo-Cavia et al., 2010; Polo-Cavia and Gomez-Mestre, 
2014). Control water was prepared following the same procedure but without placing dragonflies in the aquaria.

\subsection{Experimental procedure}

Experimental tadpoles $(\mathrm{n}=75$; Gosner stages $30-35)$ were randomly assigned to five treatments $(\mathrm{n}=15$ each) consisting of water containing HA (Sigma Aldrich, 53680) or AN (Merck,101188) at different concentrations ('HA-20 mg/L', 'HA-200 mg/L', 'AN-20 mg/L' or 'AN-80 mg/L') and a "control” treatment consisting in carbon-filtered dechlorinated tap water. For each pollution treatment, we compared swimming activity of each individual tadpole across two predator cue treatments ('presence' vs. 'absence' of water-borne chemical cues from dragonflies), in random order. Concentrations of pollutants were selected based on previous studies to avoid lethal effects on tadpoles and according to ecologically realistic levels (Ortiz et al., 2004; Fisher et al., 2006; Fabian et al., 2007; Relyea and Edwards, 2010). For example, concentrations of HA in freshwater ecosystems can fluctuate from trace levels to over $200 \mathrm{mg} / \mathrm{L}$, being highly variable in both space and time (Thomas 1997; Steinberg 2003).

Experiments took place in grey, U-shaped gutters $(101 \times 11.4 \times 6.4 \mathrm{~cm})$ sealed at both ends with plastic caps and marked inside to visually divide them into five equal parts. Gutters were filled either with $3 \mathrm{~L}$ of carbon-filtered dechlorinated tap water, or with $3 \mathrm{~L}$ of dechlorinated tap water supplemented with HA or AN depending on the pollution treatment. Then, we added $10 \mathrm{~mL}$ of control water or predator cue water to each end of each gutter (two frozen aliquots per gutter) to favor cue diffusion. We waited $5 \mathrm{~min}$ for the aliquots to thaw entirely, and then, we placed a single tadpole in the middle of each gutter, waiting another $5 \mathrm{~min}$ before the trials to allow tadpoles to 
acclimate. For the trials, we recorded activity of each individual tadpole during $30 \mathrm{~min}$, registering every $1 \mathrm{~min}$ the quadrant that each tadpole occupied in the gutter ( 30 scans per tadpole in total). We then calculated swimming activity of tadpoles from the number of marks crossed by each tadpole in each trial. This scan sampling method is widely used to measure activity rates and reasonably approximates continuous sampling (Rohr and Madison, 2001; Gonzalo et al., 2007; Polo-Cavia et al., 2010; Polo-Cavia and Gomez-Mestre, 2014). Gutters were thoroughly cleaned after each trial to eliminate residual pollutants or predator chemical cues. All behavioral observations in the study were carried out blindly so that the observer was unaware of the type of cue placed in each gutter in each trial.

\subsection{Data analysis}

To compare swimming activity of tadpoles (i.e., number of marks crossed by tadpoles over the total observation time) in the presence or absence of predator cues, and at different concentrations of contaminants in water, we used a two-way repeated measures analysis of variance with predator cue treatment (two levels: 'presence' vs. 'absence' of dragonfly cues) as a within-subject factor, and with pollution treatment (five levels: clean water, HA-20 mg/L, HA-200 mg/L, N-20 mg/L, AN-80 mg/L) as a between-subject factor. We checked data normality using Kolmogorov-Smirnov test ( $p$ $\geq 0.2$ for all variables) and verified homogeneity of variances with Levene's test ( $p \geq$ 0.37 for all variables). Post hoc pairwise comparisons among treatments were made using Tukey’s honestly significant difference tests (Sokal and Rohlf, 1995). Analyses were performed using Statistica 8.0 software. 


\section{Results}

We found a significant interaction between predator cues and presence of contaminants affecting swimming activity of tadpoles (two-way repeated measures ANOVA, predator cue treatment $\mathrm{x}$ pollution treatment: $F_{4,70}=3.24, p=0.017$ ). Thus, the response to predator cues depended on the pollution treatment. In the absence of pollutants, tadpoles effectively responded to predator cues by reducing their swimming activity by an average of $44 \%$ with respect to predator absence (Tukey's test, $p=0.02$; Fig.1). In contrast, in presence of either HA or AN pollutant, tadpoles maintained high activity levels (i.e., remained unresponsive) when exposed to predator cues ( $p \geq 0.96$ in all cases; Fig. 1). Post-hoc tests also indicated that tadpole activity remained unchanged when either HA or AN were added to the water, whether predators were present ( $p \geq$ 0.61 in all cases) or not ( $p \geq 0.17$ in all cases) (Fig. 1), which suggested a lack of direct toxic effects on tadpole activity. Main effects were not significant: swimming activity of tadpoles did not vary significantly in presence and absence of dragonfly cues when considered across all pollutant levels together (predator cue treatment, $F_{1,70}=2.82, p=$ 0.1 , and tadpoles did not alter their activity as a consequence of pollutants either (pollution treatment, $F_{4,70}=1.42, p=0.24$ ).

\section{Discussion}

Our findings demonstrate that chemical pollutants in aquatic systems interfere with the innate behavioral response of amphibian prey to cues from a native odonate predator. Spadefoot toad tadpoles responded to the presence of dragonfly cues by steeply reducing their swimming activity ( $44 \%$ reduction on average), but only in the 
absence of pollutants (Fig.1). In contrast, when HA or AN were present in the water, tadpoles remained unresponsive to predator cues, suggesting that sublethal levels of chemical pollution impair cue recognition systems of tadpoles, hence compromising their ability to detect and respond to common predators.

High activity levels increase prey detectability and the probability of encountering a predator (Taylor, 1984; Anholt and Werner, 1995), thus predicting a decrease in tadpole survival when exposed to HA and $\mathrm{AN}$ at concentrations within the range of those used in this study. Therefore, a higher impact of predation would be expected in amphibian populations inhabiting water bodies affected by agricultural runoff carrying these pollutants, even if at low concentrations. This prediction needs to be tested in future experiments considering also the effects of pollutants on predator behavior (Ujszegi et al., 2015), by assessing tadpole survival against predators when both predator and prey are exposed to chemical contaminants.

Previous studies on amphibians have examined the effects of pesticides on predator-prey interactions, suggesting that sublethal concentrations of pollutants in combination with exposure to predator cues may act synergistically to decrease survival (Relyea and Mills, 2001; Relyea, 2003a,2005). Other studies have found that pesticides can increase predation rates, but the underlying mechanisms responsible for such effects are unknown (Broomhall, 2002, 2004; Mandrillon and Saglio, 2007; Ortiz-Santaliestra et al., 2010). Some studies to date have investigated the effect of chemically altered environments on predator recognition (reviewed in Lürling, 2012). Leduc et al. (2004, 2006, 2007) and Brown et al. (2012) reported that response to alarm cues and learned recognition of novel predators by salmonids can be impaired under reduced $\mathrm{pH}$ conditions. Also, elevated $\mathrm{CO}_{2}$ causes fish to fail to respond to predation cues (Dixson et al., 2010; Ferrari et al., 2011). In amphibians, Mandrillon and Saglio (2007) found 
that the presence of sublethal concentrations of an herbicide impaired the acquired recognition of a non-native predator by Bufo bufo tadpoles. More recently, Troyer and Turner (2015) have shown that water quality (i.e., pH and conductivity) affects the magnitude of antipredator responses by tadpoles of Hyla versicolor. To our knowledge, our study is the first to demonstrate interference of innate defensive behavior against local predators by amphibian larvae due to exposure to organic chemical pollutants. A review of the literature further suggests that typical pesticides, herbicides and heavy metals present in natural waters can similarly act as disruptors of inducible defenses in larval amphibians (Lefcort et al., 1998; Raimondo et al., 1998; Lürling, 2012). Within this frame, our findings provide a potential mechanism explaining why chemical exposure can increase predation rates in amphibian populations.

With regard to toxic effects of pollutants, we found no evidence for alteration of tadpole swimming activity in the non-predator treatment associated with the presence of HA or AN (Fig. 1). Activity rates of tadpoles have been observed to decrease dosedependently in presence of pesticides (Relyea and Edwards, 2010). Nevertheless, other studies using much lower concentrations have found no effect of pesticides on tadpole activity (Hanlon and Relyea, 2013), suggesting that the effect is dependent upon the type of pollutant and its concentration. The concentrations of HA and AN in our study seem to have been too low to cause a rapid toxic effect, based on tadpole behavior, although concentrations were high enough to impair the response of tadpoles to predator cues.

Anthropogenic chemicals such as HA or AN are pervasive in freshwater ecosystems worldwide, greatly affecting amphibian habitats (Harris et al., 1998; Relyea, 2003b; Relyea and Hoverman, 2006). Sublethal concentrations of these pollutants may be hardly detectable in the short-term by conservation programs since they cause no 
immediate or visible impacts on wildlife populations, but have the potential for causing important damage by severely disturbing the chemical environment. The capacity of aquatic prey to reliably recognize water-borne chemical cues from predators is critical to survival because it allows the activation of adaptive inducible defenses (i.e., plastic changes in life history, morphology or behavior), and consequently reduces the risk of predation (Gomez-Mestre and Diaz-Paniagua, 2011; Polo-Cavia and Gomez-Mestre, 2014). Hence, even slight concentrations of pollutants may pose a threat to tadpole survival against predators, threatening the long-term persistence of amphibian populations.

While most toxicological studies have pointed out the physiological effects of pesticides as a factor responsible for amphibian declines (e.g., Perkins et al., 2000; Fordham et al., 2001; Sparling et al., 2001, 2010; Ortiz-Santaliestra et al., 2011; EgeaSerrano et al., 2012), indirect impacts of sublethal doses of pollutants disrupting tadpoles' ability to detect natural predators might be a key contributing factor explaining the local extinction of many amphibian populations in the last decades. Given that aquatic organisms are likely exposed to several chemicals combined (Hayes et al., 2006; Relyea, 2009; Rasmussen et al., 2015), our study may underestimate the indirect effects of pollutants and their interactions on survival of aquatic prey mediated through impacts on their chemically-based predator recognition systems. Further studies exploring the actual effects of these chemical mixtures on the sensory systems of aquatic prey, along with their effects on the predators themselves, will ultimately elucidate the relative role of sublethal levels of water pollution on prey population viability. 


\section{Acknowledgements}

We thank R. Arribas, L. Asencio and C. Diaz-Paniagua for their help in the field and with animal husbandry, and two anonymous reviewers for their helpful comments. Logistical support for the behavioral assays in dependencies of the Scientific Collections at Doñana Biological Station was granted by C. Ibanez and J. Cabot, and P. Fitze contributed useful comments on the manuscript. Financial support was provided by the Spanish Ministry of Science and Innovation (MICINN), Grant CGL2009-11123, and by the Universidad Autónoma de Madrid, Short Stay Grant, and the MICINN, Grant CGL2011-25062, to NPC.

\section{References}

Anholt, B.R., Werner, E.E., 1995. Interaction between food availability and predation mortality mediated by adaptive behavior. Ecology 76, 2230-2234.

Atiyeh, R.M., Lee, S., Edwards, C.A., Arancon, N.Q., Metzger, J.D., 2002. The influence of humic acids derived from earthworm-processed organic wastes on plant growth. Bioresour. Technol. 84, 7-14.

Baker, N.J., Bancroft, B.A., Garcia, T.S., 2013. A meta-analysis of the effects of pesticides and fertilizers on survival and growth of amphibians. Sci. Total Environ. 449, 150-156.

Bishop, C.A., Mahony, N.A., Struger, J., Ng, P., Pettit, K.E., 1999. Anuran development, density and diversity in relation to agricultural activity in the Holland River watershed, Ontario, Canada (1990-1992). Environ. Monit. Assess. 57, 21-43.

Boone, M.D., Bridges, C.M., 2003. Effects of carbaryl on green frog (Rana clamitans) tadpoles: timing of exposure versus multiple exposures. Environ. Toxicol. Chem. 22, 2695-2702. 
Boone, M.D., Bridges, C.M., 2006. Examining multiple sublethal contaminants on the gray treefrog (Hyla versicolor): effects of an insecticide, herbicide, and fertilizer. Environ. Toxicol. Chem. 25, 3261-3265.

Boone, M.D., James, S.M., 2003. Interactions of an insecticide, herbicide, and natural stressors in amphibian community mesocosms. Ecol. Appl. 13, 829-841.

Boone, M.D., Semlitsch, R.D., 2001. Interactions of an insecticide with larval density and predation in experimental amphibian communities. Conserv. Biol. 15, 228-238.

Boone, M.D., Semlitsch, R.D., 2002. Interactions of an insecticide with competition and pond drying in amphibian communities. Ecol. Appl. 12, 307-316.

Boone, M.D., Bridges, C.M., Rothermel, B.B., 2001. Growth and development of larval green frogs (Rana clamitans) exposed to multiple doses of an insecticide. Oecologia 129, 518524.

Bridges, C.M., 1999. Predator-prey interactions between two amphibian species: effects of insecticide exposure. Aquat. Ecol. 33, 205-211.

Brönmark, C., Hansson, L.A., 2000. Chemical communication in aquatic systems: an introduction. Oikos 88, 103-109.

Broomhall, S.D., 2002. The effects of endosulfan and variable water temperature on survivorship and subsequent vulnerability to predation in Litoria citropa tadpoles. Aquat. Toxicol. 61, 243-250.

Broomhall, S.D., 2004. Egg temperature modifies predator avoidance and the effects of the insecticide endosulfan on tadpoles of an Australian frog. J. Appl. Ecol. 41, 105-113.

Brown, G.E., Elvidge, C.K., Ferrari, M.C.O., Chivers, D.P., 2012. Understanding the importance of episodic acidification on fish predator-prey interactions: does weak acidification impair predator recognition? Sci. Tot. Environ. 439, 62-66.

Carpenter, S.R., Stanley, E.H., Zanden, M.J.V., 2011. State of the world's freshwater ecosystems: physical, chemical, and biological changes. Annu. Rev. Environ. Res. 36, 75-99. 
Chivers, D.P., Smith, R.J.F., 1998. Chemical alarm signalling in aquatic predator-prey systems: a review and prospectus. Ecoscience 5, 338-352.

Chivers, D.P., Zhao, X., Brown, G.E., Marchant, T.A., Ferrari, M.C.O., 2008. Predator-induced changes in morphology of a prey fish: the effects of food level and temporal frequency of predation risk. Evol. Ecol. 22, 561-574.

Davidson, C., 2004. Declining downwind: amphibian population declines in California and historical pesticide use. Ecol. Appl. 14, 1892-1902.

De Solla, S.R., Pettit, K.E., Bishop, C.A., Cheng, K.M., Elliott, J.E., 2002. Effects of agricultural runoff on native amphibians in the lower Fraser River Valley, British Columbia, Canada. Environ. Toxicol. Chem. 21, 353-360.

Diamond, M.L., de Wit, C.A., Molander, S., Scheringer, M., Backhaus, T., Lohmann, R., Arvidsson, R., Bergman, A., Hauschild, M., Holoubek, I., Persson, L., Suzuki, N., Vighi, M., Zetzsch, C., 2015. Exploring the planetary boundary for chemical pollution. Environ. Int. 78, 8-15.

Diana, S.G., Resetarits, W.J., Shaeffer, D.J., Beckmen, K.B., Beasley, V.R., 2000. Effects of atrazine on amphibian growth and survival in artificial aquatic communities. Environ. Toxicol. Chem. 19, 2961-2967.

Dixson, D.L., Munday, P.L., Jones, G.P., 2010. Ocean acidification disrupts the innate ability of fish to detect predator olfactory cues. Ecol. Lett. 13, 68-75.

Dodson, S.I., Hanazato, T., Gorski, P.R., 1995. Behavioral responses of Daphnia pulex exposed to carbaryl and Chaoborus kairomone. Environ. Toxicol. Chem. 14, 43-50.

Egea-Serrano, A., Relyea, R.A., Tejedo, M., Torralva, M., 2012. Understanding the impact of chemicals on amphibians: a meta-analytic review. Ecol. Evol. 2, 1382-1397.

Fabian, N.J., Albright, L.B., Gerlach, G., Fisher, H.S., Rosenthal, G.G., 2007. Humic acid interferes with species recognition in zebrafish (Danio rerio). J. Chem. Ecol. 33, 20902096.

Ferrari, M.C.O., Wisenden, B.D., Chivers, D.P., 2010. Chemical ecology of predator-prey interactions in aquatic ecosystems: a review and prospectus. Can. J. Zool. 88, 698-724. 
Ferrari, M.C.O., McCormick, M.I., Munday, P.L., Meekan, M.G., Dixson, D.L., Lonnstedt, O.M., et al., 2011. Putting prey and predator into the CO2 equation -quantitative and qualitative effects of ocean acidification on predator-prey interactions. Ecol. Lett. 14, $1143-1148$.

Fisher, H.S., Wong, B.B.M., Rosenthal, G.G., 2006. Alteration of the chemical environment disrupts communication in a freshwater fish. Proc. R. Soc. Lond. B 273, 1187-1193.

Fordham, C.L., Tessari, J.D., Ramsdell, H.S., Keefe, T.J., 2001. Effects of malathion on survival, growth, development, and equilibrium posture on bullfrog tadpoles (Rana catesbeiana). Environ. Toxicol. Chem. 20, 179-184.

Gill, R., Raine, N.E., 2014. Chronic impairment of bumblebee natural foraging behaviour induced by sublethal pesticide exposure. Funct. Ecol. 28, 1459-1471.

Gomez-Mestre, I., Diaz-Paniagua, C., 2011. Invasive predatory crayfish do not trigger inducible defences in tadpoles. Proc. R. Soc. Lond. B 278, 3364-3370.

Gonzalo, A., López, P., Martín, J., 2007. Iberian green frog tadpoles may learn to recognize novel predators from chemical alarm cues of conspecifics. Anim. Behav. 74, 447-453.

Gosner, K.L., 1960. A simplified table for staging anuran embryos and larvae with notes on identification. Herpetologica 16, 183-190.

Griffis-Kyle, K.L., 2005. Ontogenic delays in effects of nitrite exposure on tiger salamanders (Ambystoma tigrinum tigrinum) and wood frogs (Rana sylvatica). Environ. Toxicol. Chem. 24, 1523-1527.

Hanlon, S.M., Relyea, R.A., 2013. Sublethal effects of pesticides on predator-prey interactions in amphibians. Copeia 2013, 691-698.

Harris, M.L., Bishop, C.A., Struger, J., Ripley, B., Bogart, J.P., 1998. The functional integrity of northern leopard frog (Rana pipiens) and green frog (Rana clamitans) populations in orchard wetlands. II. Effects of pesticides and eutrophic conditions on early life stage development. Environ. Toxicol. Chem. 17, 1351-1363. 
Hayes, T., Case, P., Chui, S., Chung, D., Haefele, C., Haston, K., Lee, M., Mai, V.-P., Marjuoa, Y., Parker, J. et al., 2006. Pesticide mixtures, endocrine disruption, and amphibian declines: are we underestimating the impact? Environ. Health Perspect. 114, 40-50.

Hayes, T.B., Falso, P., Gallipeau, S., Stice, M., 2010. The cause of global amphibian declines: a developmental endocrinologist's perspective. J. Exp. Biol. 213, 921-933.

Hoffmann, M., Hilton-Taylor, C., Angulo, A., Böhm, M., Brooks, T.M., Butchart, S.H., et al., 2010. The impact of conservation on the status of the world's vertebrates. Science 330, 1503-1509.

Holomutzki, J.R., 1995. Ovoposition sites and fish-deterrent mechanisms in two stream anurans. Copeia 1995, 607-613.

Hubbard, P.C., Barata, E.N., Canario, A.V.M., 2002. Possible disruption of pheromonal communication by humic acid in the goldfish, Carassius auratus. Aquat. Toxicol. 60, 169-183.

Jofre, M.B., Karasov, W.H., 1999. Direct effect of ammonia on three species of North American anuran amphibians. Environ. Toxicol. Chem. 18, 1806-1812.

Johansson, B.J., Jones, T.M., 2007. The role of chemical communication in mate choice. Biol. Rev. 82, 265-289.

Joly, P., Miaud, C., Lehmann, A., Grolet, O., 2001. Habitat matrix effects on pond occupancy in newts. Conserv. Biol. 15, 239-248.

Kappler, A., Haderlein, S.B., 2003. Natural organic matter as reductant for chlorinated aliphatic pollutants. Environ. Sci. Technol. 37, 2714-2719.

Kats, L.B., Dill, L.M., 1998. The scent of death: chemosensory assessment of predation by prey animals. Ecoscience 5, 361-394.

Kerby, J.L., Hart, A.J., Storfer, A., 2011. Combined effects of virus, pesticide, and predator on the larval tiger salamander (Ambystoma tigrinum). Ecohealth 8, 46-54.

Kiesecker, J.M., Chivers, D.P., Blaustein, A.R., 1996. The use of chemical cues in predator recognition by western toad tadpoles. Anim. Behav. 52, 1237-1245. 
Kolpin, D.W., Furlong, E.T., Meyer, M.T., Thurman, E.M., Zaugg, S.D., Barber, L.B., Buxton, H.T., 2002. Pharmaceuticals, hormones, and other organic wastewater contaminants in U. S. streams, 1999-2000: a national reconnaissance. Environ. Sci. Technol. 36, 12021211.

Laposata, M.M., Dunson, W.A., 2000. Effects of spray-irrigated wastewater effluent on temporary pond-breeding amphibians. Ecotoxicol. Environ. Saf. 46, 192-201.

Lass, S., Vos. M., Wolinska, J., Spaak, P., 2005. Hatching with the enemy: Daphnia diapausing eggs hatch in the presence of fish kairomones. Chemoecology 15, 7-12.

Leduc, A.O.H.C., Ferrari, M.C.O., Kelly, J.M., Brown, G.E., 2004. Learning to recognize novel predators under weakly acidic conditions: the effect of reduced $\mathrm{pH}$ on acquired predator recognition by juvenile rainbow trout. Chemoecology $14,107-112$.

Leduc, A.O.H.C., Roh, E., Harvey, M.C., Brown, G.E., 2006. Impaired detection of chemical alarm cues by juvenile wild Atlantic salmon (Salmo salar) in a weakly acidic environment. Can. J. Fisheries Aquat. Sci. 63, 2356-2363.

Leduc, A.O.H.C., Roh, E., Breau, C., Brown, G.E., 2007. Effects of ambient acidity on chemosensory learning: an example of an environmental constraint on acquired predator recognition in wild juvenile Atlantic salmon (Salmo salar). Ecol. Fresh. Fish 16, 385394.

Lefcort, H., Meguire, R.A., Wilson, L.H., Ettinger, W.F., 1998. Heavy metals alter the survival, growth, metamorphosis, and antipredator behavior of Columbia spotted frog (Rana luteiventris) tadpoles. Arch. Environ. Contam. Toxicol. 35, 447- 456.

Lürling, M., 2012. Infodisruption: pollutants interfering with the natural chemical information conveyance in aquatic systems. In: Brönmark, C., Hansson, L.A. (Eds.), Chemical ecology in aquatic systems. Oxford University Press, New York, pp. 250-271.

Lürling, M., Scheffer, M., 2007. Info-disruption: pollution and the transfer of chemical information between organisms. Trends. Ecol. Evol. 22, 374-379.

Mandrillon, A-L., Saglio, P., 2007. Herbicide exposure affects the chemical recognition of a non native predator in common toad tadpoles Bufo bufo. Chemoecology 17, 31-36. 
Marco, A., Quilchano, C., Blaustein, A.R., 1999. Sensitivity to nitrate and nitrite in pondbreeding amphibians from the Pacific Northwest, USA. Environ. Toxicol. Chem. 18, $2836-2839$.

McCoy, M.W., Touchon, J.C., Landberg, T., Warkentin, K.M., Vonesh, J.R., 2012. Prey responses to predator chemical cues: disentangling the importance of the number and biomass of prey consumed. Plos One 7, e47495.

Mesquita, R., Canario, A.V.M., Melo, E., 2003. Partition of fish pheromones between water and aggregates of humic acids. Consequences for sexual signaling. Environ. Sci. Technol. $37,742-746$.

Miaud, C., Oromí, N., Navarro, S., Sanuy, D., 2011. Intra-specific variation in nitrate tolerance in tadpoles of the Natterjack toad. Ecotoxicology 20, 1176-1183.

Millennium Ecosystem Assessment, 2005. Ecosystems and human well-being: synthesis. Island Press, Washington, DC.

Ortiz, M.E., Marco, A., Saiz, N., Lizana, M., 2004. Impact of ammonium nitrate on growth and survival of six European amphibians. Archiv. Environ. Contam. Toxicol. 47, 234-239.

Ortiz-Santaliestra, M.E., Marco, A., Fernández-Benéitez, M.J., Lizana, M., 2007. Effects of ammonium nitrate exposure and water acidification on the dwarf newt: the protective effect of oviposition behaviour on embryonic survival. Aquat. Toxicol. 85, 251-257.

Ortiz-Santaliestra, M.E., Fernández-Benéitez, M.J., Marco, A., Lizana, M., 2010. Influence of ammonium nitrate on larval anti-predatory responses of two amphibian species. Aquat. Toxicol. 99, 198-204.

Ortiz-Santaliestra, M.E., Marco, A., Lizana, M., 2011. Realistic levels of a fertilizer impair Iberian newt embryonic development. Herpetologica 67, 1-9.

Peacor, S.D., Allesina, S., Riolo, R.L., Pascual, M., 2006. Phenotypic plasticity opposes species invasions by altering fitness surface. Plos Biol 4, e372.

Perkins, P.J., Boermans, H.J., Stephenson, G.R., 2000. Toxicity of glyphosate and triclopyr using the frog embryo teratogenesis assay-Xenopus. Environ. Toxicol. Chem. 19, 940945. 
Polo-Cavia, N., Gomez-Mestre, I., 2014. Learned recognition of introduced predators determines survival of tadpole prey. Funct. Ecol. 28, 432-439.

Polo-Cavia, N., Gonzalo, A., López, P., Martín, J., 2010. Predator-recognition of native but not invasive turtle predators by naïve anuran tadpoles. Anim. Behav. 80, 461-466.

Preston, B.L., Cecchine, G., Snell, T.W., 1999a. Effects of pentachlorophenol on predator avoidance behavior of the rotifer Brachionus calyciflorus. Aquat. Toxicol. 44, 201-212.

Preston, B.L., Snell, T.W., Dusenbery, D., 1999b. The effects of sublethal pentachlorophenol exposure on predation risk in freshwater rotifer species. Aquat. Toxicol. 47, 93-105.

Raimondo, S.M., Rowe, C.L., Congdon, J.D., 1998. Exposure to coal ash impacts swimming performance and predator avoidance in larval bullfrogs (Rana catesbeiana). J. Herpetol. $32,289-292$.

Rasmussen, J.J., Wiberg-Larsen, P., Baattrup-Pedersen, A., Cedergreen, N., McKnight, U.S., Kreuger, J., Jacobsen, D., Kristensen, E.A., Friberg, N., 2015. The legacy of pesticide pollution: an overlooked factor in current risk assessments of freshwater systems.

Water. Res. 84, 25-32.

Relyea, R.A., 2003a. Predator cues and pesticides: a double dose of danger for amphibians. Ecol. Appl. 13, 1515-1521.

Relyea, R.A., 2003b. How prey respond to combined predators: a review and an empirical test. Ecology 84, 1827-1839.

Relyea, R.A., 2005. The lethal impacts of roundup and predatory stress on six species of North American tadpoles. Archiv. Environ. Contam. Toxicol. 48, 351-357.

Relyea, R.A., 2009. A cocktail of contaminants: how mixtures of pesticides at low concentrations affect aquatic communities. Oecologia 159, 363-376.

Relyea, R.A., Edwards, K., 2010. What doesn't kill you makes you sluggish: how sublethal pesticides alter predator-prey interactions. Copeia 2010, 558-567.

Relyea, R.A., Hoverman, J., 2006. Assessing the ecology in ecotoxicology: a review and synthesis in freshwater systems. Ecol. Lett. 9, 1157-1171. 
Relyea, R.A., Mills, N., 2001. Predator-induced stress makes the pesticide carbaryl more deadly to gray treefrog tadpoles (Hyla versicolor). Proc. Natl. Acad. Sci. U. S. A. 98, 24912496.

Relyea, R.A., Schoeppner, N.M., Hoverman, J.T., 2005. Pesticides and amphibians: the importance of community context. Ecol. Appl. 15, 1125-1134.

Rohr, J.R., Crumrine, P.W., 2005. Effects of an herbicide and an insecticide on pond community structure and processes. Ecol. Appl. 15, 1135-1147.

Rohr, J.R., Madison, D.M., 2001. A chemically mediated trade-off between predation risk and mate search in newts. Anim. Behav. 62, 863-869.

Schulz, R., Dabrowski, J.M., 2001. Combined effects of predatory fish and sublethal pesticide contamination on the behavior and mortality of mayfly nymphs. Environ. Toxicol. Chem. 20, 2537-2543.

Seehausen, O., Van Alphen, J.J.M., Witte, F., 1997. Cichlid fish diversity threatened by eutrophication that curbs sexual selection. Science 277, 1808-1811.

Sih, A., Moore, R.D., 1993. Delayed hatching of salamander eggs in response to enhanced larval predation risk. Am. Nat. 142, 947-960.

Sih, A., Ferrari, M.C.O., Harris, D.J., 2011. Evolution and behavioural responses to humaninduced rapid environmental change. Evol. Appl. 4, 367-387.

Smith, G.R., Temple, K.G., Dingfelder, H.A., Vaala, D.A., 2006. Effects of nitrate on the interactions of the tadpoles of two ranids (Rana clamitans and $R$. catesbeiana). Aquat. Ecol. 40, 125-130.

Sokal, R.R., Rohlf, F.J., 1995. Biometry, 3rd edn. WH Freeman, New York.

Sparling, D.W., Fellers, G.M., McConnell, L.L., 2001. Pesticides and amphibian population declines in California, USA. Environ. Toxicol. Chem. 20, 1591-1595.

Sparling, D.W., Linder, G., Bishop, C.A., Krest, S.K., 2010. Ecotoxicology of amphibians and reptiles, 2nd edn. SETAC/Taylor and Francis, Florida.

Stauffer, H.P., Semlitsch, R.D., 1993. Effects of visual, chemical and tactile cues of fish on the behavioural responses of tadpoles. Anim. Behav. 46, 355-364. 
Taylor, R.J., 1984. Predation. Chapman and Hall, London.

Thomas, J.D., 1997. The role of dissolved organic matter, particularly free amino acids and humic substances, in freshwater ecosystems. Freshwater Biol. 38, 1-36.

Tollrian, R., Harvell, C.D., 1999. The evolution of inducible defenses. Princeton University Press, Princeton, NJ.

Troyer, R.R., Turner, A.M., 2015. Chemosensory perception of predators by larval amphibians depends on water quality. Plos One 10, e0131516.

Ujszegi, J., Gál, Z., Mikó, Z. and Hettyey, A., 2015. No observable effect of a glyphosate-based herbicide on two top predators of temporal water bodies. Environ. Toxicol. Chem. 34, 307-313.

Van Buskirk, J., Arioli, M., 2002. Dosage response of an induced defense: how sensitive are tadpoles to predation risk? Ecology 83, 1580-1585.

Ward, A.J.W., Duff, A.J., Horsfall, J.S., Currie, S., 2008. Scents and scents-ability: pollution disrupts chemical social recognition and shoaling in fish. Proc. R. Soc. Lond. B 274, $101-105$.

Wilson, D.J., Lefcort, H., 1993. The effect of predator diet on the alarm response of red-legged frog, Rana aurora tadpoles. Anim. Behav. 46, 1017-1019.

Wolf, M.C., Moore, P.A., 2002. Effects of the herbicide metolachlor on the perception of chemical stimuli by Orconectes rusticus. J. N. Am. Benthol. Soc. 21, 457-467.

Woody, D.R., Mathis, A., 1998. Acquired recognition of chemical stimuli from an unfamiliar predator: associative learning by adult newts, Notophthalmus viridiscens. Copeia 1998, $1027-1031$.

Wyatt, T., 2003. Pheromones and animal behavior. Cambridge University Press, Cambridge, UK.

Yang, M.L., Huang, T.S., Lee, Y.S., Chen, T.H., Chen, S.Y., Lu, F.J., 2002. Inhibition of endogenous thyroid hormone receptor-beta and peroxisome proliferator-activated receptor-alpha activities by humic acid in a human derived liver cell line. Thyroid 12, $361-371$ 
Fig. 1. Activity levels (mean \pm SE number of marks crossed during $30 \mathrm{~min}$ ) of Pelobates cultripes tadpoles in water with different concentrations of a) humic acid and b) ammonium nitrate, in presence and absence of chemical cues from a common predator (Anax imperator). Bars labelled with different letters differed significantly from one another.

a) Humic acid

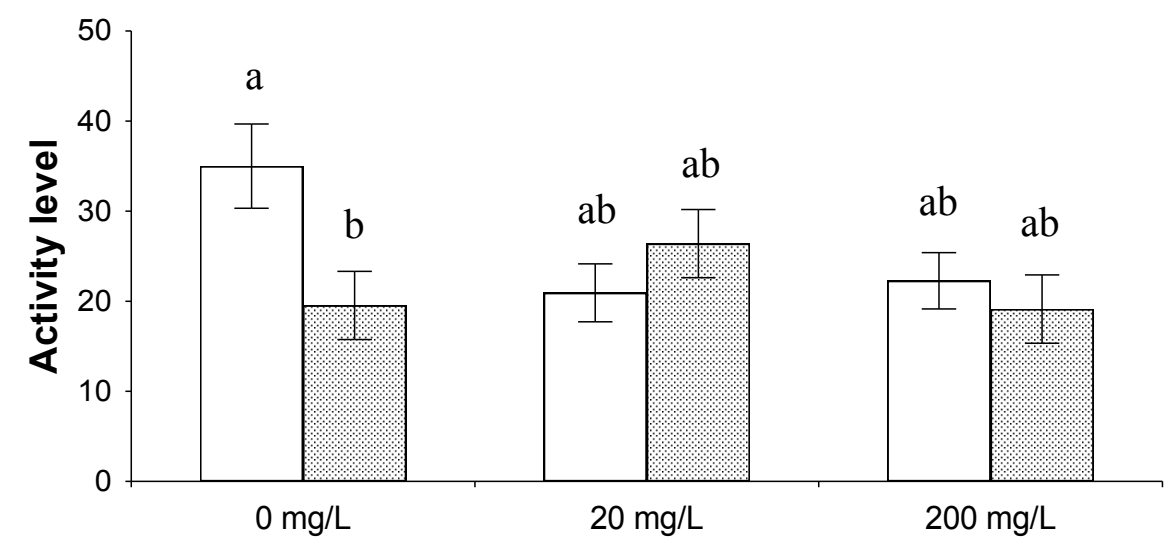

b) Ammonium nitrate

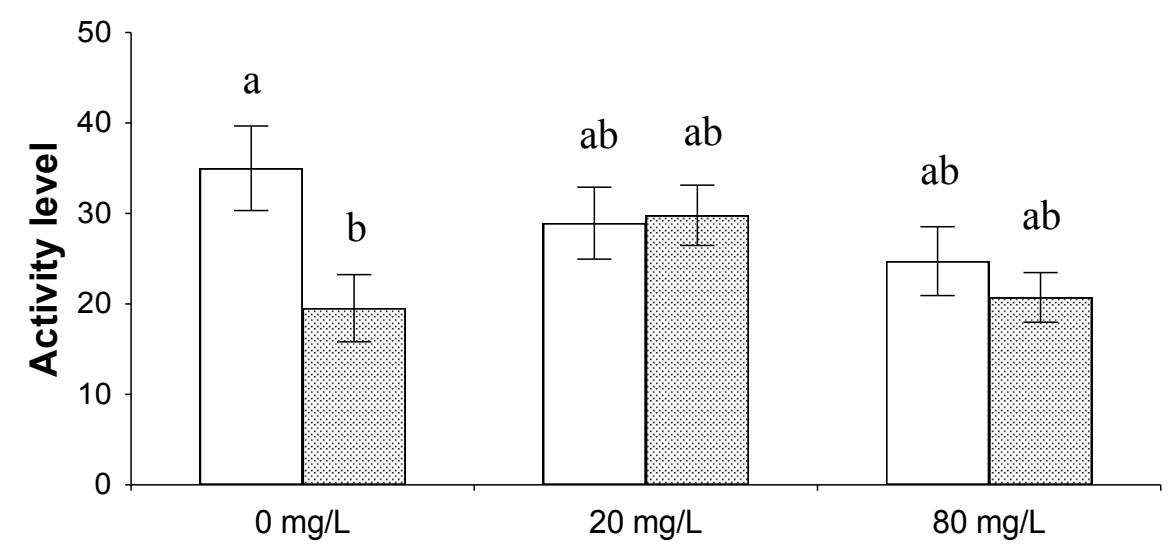

non-predator predator 